\title{
AUXILIARIES AND OTHER CATEGORIES IN STRAITS SALISHAN ${ }^{1}$
}

\author{
TIMOTHY MONTLER
}

\author{
UNIVERSITY OF NORTH TEXAS
}

\begin{abstract}
Tests for category membership in Klallam and Northern Straits can be found in the distribution of the constituents of what have been called complex predicates, the first element of which typically has no overt morphology. Among these first elements we can identify a category of auxiliary and three categories of nonpredicative, adverbial intensifier. Verbs, as opposed to nominal and adjectival lexical items, can be identified as the class of lexical items that may follow auxiliaries. Among the remaining lexical items, nouns can be distinguished from adjectives and adjectives from auxiliaries by syntactic position and, in certain constructions, number agreement.

[KeYwORDS: Straits, Klallam, Saanich, Salish, auxiliary, noun, verb, adjective, adverb, category, constructions, complex predicates]
\end{abstract}

1. Introduction. Thompson and Thompson (1971), in their sketch of Klallam, found it useful to consider just two kinds of words: full predicates and particles. They find no other categories necessary. Jelinek and Demers (1994), with examples from Northern Straits, demonstrate much of the ample evidence for the absence of categories in support of the pronominal argument hypothesis.

These two languages, Klallam and Northern Straits, are very closely related languages of the Straits subgroup of Central Salishan. ${ }^{2}$ This paper describes classes of words in the Straits languages that have been traditionally called "auxiliaries" and shows that their distribution provides evidence that there are distinct categories of verb, noun, and adjective in these languages and that there are straightforward tests for identifying them. The data come from Klallam, but the facts are essentially the same in Northern Straits.

1.1. The categories problem in Salishan languages. The problem of finding evidence for grammatical categories in Salishan languages is well known and frequently mentioned in Salishan and typological literature. Kuipers (1968), Jacobsen (1979), and Kinkade (1983) are most frequently

${ }^{1}$ All data presented here are from fieldwork that has been supported by grants from the National Science Foundation, National Endowment for the Humanities, the Whatcom Museum Jacobs Fund, and the University of North Texas. I thank Ivy Doak, the IJAL anonymous referees, and participants of the Thirty-sixth International Conference on Salish and Neighbouring Languages (2001) and the 2002 SSILA meeting for comments on earlier versions of this paper.

${ }^{2}$ See Montler (1999) for details on how these two languages are alike and different. 
cited. Kuipers and Kinkade present the case against a noun/verb distinction. Jacobsen summarizes the long history of discussion of categories in the languages of the Northwest North American linguistic area and is the first to argue explicitly for a distinction between nouns and verbs in Nootkan and Salishan.

Among Salishanists who have argued for the existence of grammatical categories in several of the languages are: Van Eijk and Hess (1986), who find semantic categories noun and verb in Lillooet and Lushootseed, but without, as they say, syntactic significance; Mattina and Mattina (1995), who find a morphological test for Okanagan in a pair of prefixes that are similar in sound and meaning, where one occurs on nouns and the other on verbs; and Matthewson and Demirdache (1995) and Davis, Lai, and Matthewson (1997), who find syntactic evidence of nouns for St'at'mcets (Lillooett). ${ }^{3}$

A linguist not working on or new to Salishan languages might wonder, given Jacobsen (1979) and the other arguments for categories in Salishan languages, why some Salishanists maintain category neutrality. The problem is nicely understated by Matthewson and Demirdache: "the evidence for the distinctions between NP, AP, and VP . . is very subtle. In contrast, the evidence for category neutrality . . . is overt" (1995:75).

1.2. The s- prefix as a category test. Before beginning the particular topic of this paper - the description of the auxiliaries in the Straits languages and how their distribution provides evidence for category distinctions-I think it will be useful to give a sample of some of the facts that allow some Salishanists to maintain category neutrality. The following short discussion of the $s$ - prefix illustrates the difficulties in finding a simple and robust test for categories in Salishan languages.

Jacobsen (1979) presents evidence for categories that is applicable to Salishan in general. Although he principally discusses the neighboring Nootkan languages, where category distinctions are also difficult, he briefly

\footnotetext{
${ }^{3}$ The argument for categories in Northern Straits presented in Haag (1998) is vitiated by a lack of familiarity with the language. There, the author presumed that $\mathrm{C} 2 \mathrm{C}$ - reduplication regularly indicates plural in the Straits languages and then looked at that pattern of reduplication in two Northern Straits words: náqəə⿱一土 'dive' and sténi? 'woman'. Since the glosses for the reduplicated form of the former word are aspectual and the latter plural, this is taken as evidence that the two belong to different categories.

Actually, both naqnáqay and stanténi? can have the 'collective plural' or the 'repetitive' aspectual interpretations. Haag states: "if all lexical items are undifferentiated predicates ... we should get both 'dive repeatedly' and 'be a woman over and over'.' In fact, we do. While naqnáqay means 'they dive' or 'dive again and again' or 'be one dive after another', stanténi? can mean 'they are a bunch of women' (in its collective plural interpretation) OR 'be one woman after another'.
} 
discusses (1979:96-104) the pan-Salishan /s-/ prefix as a nominalizer and as evidence for a category noun.

Some words like the word for 'eat' require the prefix before the possessive morphology can be attached. Other words do not allow the $s$ - prefix. Examples (1) and (2) are from Klallam. In these and the following examples, the $s$ - prefix in question is in boldface.

(1) Titn 'eat' tán 'mother'

(2) ns'îtn 'my food' (*n'ittn) ntán 'my mother' (*nstán)

In (1), the words for 'eat' and 'mother' do not have the $s$-. In (2), the word for 'eat' must take the $s$ - before the first-person possessive can be applied, while the word for 'mother' may not take the $s$-. Therefore, according to the proposed test, we can identify the class of words that must have the $s$ - as verbs and the class that does not take the $s$ - prefix with the possessive as nouns.

This classification works for many words, but the problem is that many words with the $s$ - are not derived nouns. In Northern Straits, for example, the words swáy'qa' 'man' and sténi? 'woman' both occur with the $s$-, so they would seem to be derived nouns; but the words for 'baby boy' and 'baby girl' are the same as 'man' and 'woman' but without the $s$-: wáy'qa? and téni?. In Klallam, there are a pair of words with and without $s$ - with a

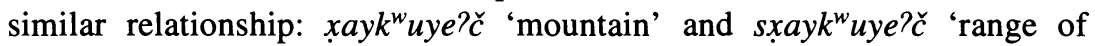
mountains'. The word sqéxa? 'dog' has the $s$ - but pús 'cat' does not; swíw'las 'young man' does, while q'é'yi? 'young woman' does not; and so on for many more examples.

Almost all words take the same morphology if semantically allowable, whether the $s$ - is present or not. (3) shows the regular form of the imperfective-a glottal stop infix.

(3) ?itn_ya?_cn.

eat_PAST_1suBJ

'I ate'.

?é?tn_ya?_cn.

'I was eating'.

The examples in (4a) and (4b) show forms with the $s$ - prefix.

(4a) sqi’ám' cə ns'ítn.

no good DET

'My food is no good'. 
(4b) sqi’ám’ co ns?é?tn.

'What I'm eating is no good'.

In $(4 a)$, the subject seems to be a noun, but in $(4 b)$, with the imperfective aspect, it seems to be a headless relative clause. The $s$ - might more economically be considered a marker of subordination rather than a nominalizer.

Example (5) shows that words with the $s$ - prefix can be main predicates with un-nounlike meaning.

(5) s?ítn_ya?_cn (?a? $\left.k^{w} s a p a p x^{w} \partial ́ y q s a n\right)$.

'I was eaten up (by mosquitoes)'.

Consultants in both Klallam and Northern Straits insist that sentences such as (5) cannot be translated 'I was food'.

Almost any word, with $s$ - and without, even proper names, even when following a determiner in an NP, can be marked for aspect and tense. Almost any word can be marked for the collective plural, diminutive, imperfective, transitive, and so on. There are cardinal numbers and even person deictic predicates, translated as first- and second-person pronouns, that may take this morphology. It not being the central purpose of this paper to recapitulate all of this evidence here, I refer the reader to Kinkade (1983), Jelinek (1990), Jelinek and Demers (1994), and especially Kuipers (1968) for more examples.

No one, as far as I know, denies that there are indeed semantic categories 'nominal' - referring to 'people, places, or things'-and 'verbal'-referring to 'actions or states'-words in Salishan languages. The problem lies in finding operational tests for morphosyntactic categories noun and verb corresponding to these semantics. Many interesting things can be said about the complex phonology and morphology of these languages without reference to categories of words. On the other hand, much of what can be said about grammatical relations and syntax in general in Salishan languages can be said simply assuming that there are nouns and verbs. We expect to find categories since languages generally distinguish categories, but the burden of proof is on those who would multiply categories.

As it turns out, words with the $s$ - prefix in the Straits Salishan languages are indeed not verbs: they reliably fail the test for Verb-hood described in $\mathbf{5}$ below. Furthermore, words with the $s$-prefix pass the test for Noun-hood described in 7.

In addition to the categories noun and verb, this paper provides evidence for several distinct categories of Auxiliary (5.1) and several categories of Adverbial Intensifier (5.2-5.5). Section 6 gives further evidence for a category distinction between true auxiliaries and the intensifiers when they occur in transitive clauses. In addition to the test for the category Noun, 7 
provides evidence for the existence of a category of Adjectives in the Straits languages.

Before I present the evidence for these categories, it is necessary to present some basic, background description of aspects of Straits Salishan grammar. Section 2 introduces the Auxiliaries, the class of words around which the arguments in this paper revolve; 3 describes the simple predicates; 4 describes what have been called complex predicates and second position clitics; 8 presents one more unrelated bit of evidence for categories; and 9 provides a summary and conclusion.

2. Auxiliaries. Thompson and Thompson (1971:263) briefly mention a class of lexical items in Klallam they call "auxiliaries," which appear in complex predicate constructions. They give four examples with this comment: "One kind of independent particle affects predicates in an important way: auxiliaries appear first in their predicates, followed by a full word as predicate center. Such predicates are complex. In such cases predicate proclitics remain bound to the predicate center, but enclitics follow rather the auxiliary."

The four examples that Thompson and Thompson give have been reelicited from native speakers and are repeated here in (6) with transcription adjusted to the current understanding of Klallam morphophonemics. ${ }^{4}$ The auxiliary and its gloss are in boldface. ${ }^{5}$

(6a) mán'_cn ?u?_qák $k^{w}$.

very_1suBJ ?u?_tired

'I'm awfully tired'.

(6b) tú? $x^{w} \_y a ? \quad ? u ?$ ? wasáys.

exactly_PAST ?u?_bark

'It [the dog] was just beginning to bark'.

(6c) čw'ín'_cn ?u?_qi?nú?yat.

even_1suBJ ?u?_angry

'Even I was angry'.

(6d) X'áy_u_cx $x^{w} \quad$ ?u?_?é?tn'?

also_QUEST_2SUBJ ?u?_eating

'Are you eating, too?'

\footnotetext{
${ }^{4}$ Only relevant morphology is indicated. An underline attaches clitics to their hosts.

${ }^{5}$ For a description of Klallam subject and object markers, see Montler (1996).
} 
Thompson (1979a) looks at the auxiliaries from a historical perspective to try to find an explanation for the varying position of subject enclitics across the Salishan languages. Of particular interest here are the Klallam examples given. One reelicited example is repeated here:

(7) hiyá?_ya?_cn t'ák $k^{w}$.

go_PAST_1SUBJ cross

'I went across'.

The auxiliary in (7) seems quite different from those in (6) in at least two respects. First, they differ semantically. In (6), it is the auxiliary that adverbially modifies the main predicate. In (7), however, it appears that it is the main predicate $t^{\prime} a k^{w} i$ that provides manner adverbial modification to the auxiliary, hiyá?. The second way they differ is syntactically. The proclitic ${ }^{2} u^{76}$ is required in the sentences in (6) but not in the one in (7). The differences between (6) and (7) suggest that we have two different constructions and two different lexical categories.

Poggi (1981) looks at some of the items in this class of words and analyzes the constructions as complex sentences with the auxiliary as the main predicate and the second predicate as subordinate. Jelinek (1990) discusses the Lummi cognates of these constructions in more detail. ${ }^{7}$ Jelinek assumes, as does Poggi, that the auxiliaries are predicates but that those in (6) are adverbial "second order predicates," not main predicates followed by subordinate clauses.

This paper explores these possibilities, describing and exemplifying these constructions in detail. I show how the two constructions in (6) and (7) are fundamentally different and how they provide evidence for the grammatical categories verb and adverbial intensifier as distinct from each other and as distinct from other contentive categories. I also show that aside from the two constructions in (6) and (7), there are at least two other similar constructions.

3. Simple predicates. Simple predicates in Klallam are basically the same as those in most other Central Salishan languages: the predicate comes first, immediately followed by zero or more speech-act enclitics. ${ }^{8}$ All

\footnotetext{
${ }^{6}$ This $7 u$ undoubtedly has the underlying form $w$ ', and it is probably a prefix rather than a clitic. These points are not relevant to this paper, therefore I present the morpheme here as traditionally done to allow for easier comparison across languages and dialects.

${ }^{7}$ The details of constructions under discussion in Klallam are essentially the same in the closely related Northern Straits dialects Saanich and Lummi. The major differences are phonological with an occasional noncognate lexical item, such as Klallam xán' and Northern Straits $m a ́ k$ 'w 'all'.

${ }^{8}$ These enclitics situate the speech act and include first- and second-person subjects, past and future tense, and various evidentials and question markers. The Klallam version of these is very similar to what were called "post-predicate particles" in Saanich (Montler 1986).
} 
but the first of the auxiliaries in (6) and (7) can also be simple predicates, as in (8).

(8a) hiyá?_ya?_cn.

go_PAST_1suBJ

'I went'.

(8b) $t u ́ 7 x^{w}-y a ?$

middle_PAST

'It was the middle'.

(8c) ̌̌w'in'_cn.

even_1suBJ

'Even I am'.

(8d) $\chi^{\prime} a ́ y \_u \_c x^{w}$ ?

also_QUEST_2SUBJ

'Are you, too?'

The second predicates in (6) and (7) can also be simple predicates, as shown in (9).

(9a) qák $k^{w}$

tired_1suBJ

'I'm tired'.

(9b) wasáys_ya?.

bark_PAST

'It [the dog] barked'.

(9c) qi?nú?ทวt_cn.

angry_1suBJ

'I was angry'.

(9d) 7éptn'_u_cx $x^{w}$ ?

eating_QUEST_1SUBJ

'Are you eating?'

(9e) t'ák $k^{w} i_{-y a}$ _cn.

cross_PAST_1sUBJ

'I crossed'.

${ }^{9}$ Tense marking is not obligatory in Klallam. Sentences unmarked for tense may be translated with any tense depending on context. 
Four types of constituents can immediately follow this simple predicate/enclitic bundle: a determiner phrase (example 10), a prepositional phrase (11), a subordinate clause (12), or a conjoined DP (13).

Up to two determiner phrases are possible: ${ }^{10}$

$$
\begin{gathered}
\text { (10a) hiyá?_ya? ca_swáy'qa? } \\
\text { go_PAST DET_man }
\end{gathered}
$$

'The man went'.

${ }^{10}$ These determiner phrases may be seen as arguments or as adjuncts indexed to pronominal arguments. If there is one, it is always coreferential with the intransitive subject and usually with the transitive object; but if the context is clear, it may be coreferential with a transitive subject. For example:

$$
\begin{array}{ll}
\text { ččát-s } & \text { ca_sút. } \\
\text { build-3suBJ } & \text { DET_road }
\end{array}
$$

'He built the road'.

But:

$$
\text { ččát-s co_ncát. }
$$

build-3SUBJ DET_my father

'My father built it'.

In the former the determiner phrase is the object, while in the latter it is the subject.

If there are two DPs, a relatively rare but certainly natural occurrence, the first, if they are of equal animacy, is indexed to the subject and the second to the object. In both Klallam and Saanich, unlike what Jelinek and Demers (1994) report for Lummi, the order of subject and object DPs in such cases is fixed. Order between the two is free when one is clearly of higher animacy than the other:

ččát-s co_ncát co_sút.

build-3SUBJ DET_my father DET_road

'My father built the road'.

Or:

ččát-s ca_sút ca_ncát.

build-3SUBJ DET_road DET_my father

'My father built the road'.

Also, the order is free when one is marked as the possessor of the other. In this case, the only interpretation allowed is where the possessor is subject and the one marked for possession is the object. For example:

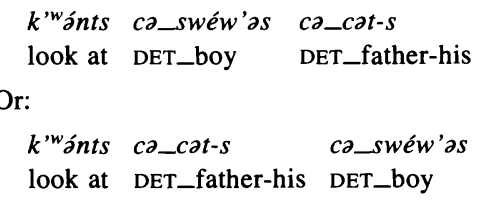

Both are interpreted as 'The boy saw his father'. It seems that the interpretation that would produce the equivalent of ' $\mathrm{His}_{\mathrm{i}}$ father saw the boy' is blocked. Whatever the explanation for this pattern, it does indicate that there is syntax involved beyond that expected of mere adjuncts. 
(10b) k’wánts ca_swáy'qa? ca_stáni.

look at DET_MAN DET_woman

'The man looked at the woman'.

A prepositional phrase is marked by the one general-purpose oblique case marker, ? $a$ ?:

(11a) hiyá?_cn ?a?_co_sút

go_1sUBJ PREP_DET_door

'I went to the door'.

(11b) k'wánnay_cn ?a?_ca_swáy'qa?.

be seen_1sUBJ PREP_DET_man

'I was seen by the man'.

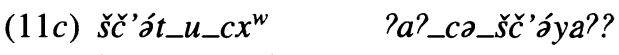

hit_QUEST_2SUBJ PREP_DET_stick

'Did you hit it with a stick?'

There are three types of non-DP subordinate clauses: 'if/when' clauses marked by the subjunctive clause indicating proclitic $k^{w} a$ ? (12a), 'while' clauses marked by the proclitic $2 \partial t(12 b)$, and subjective genitive clauses (see Montler 1996 for examples of this latter type of clause).

(12a) hiyá?_cn $k^{w} a ? \_h i y a^{\prime}-x^{w}$.

go_1SUBJ SUBORD_go-2SUBORDSUBJ

'I'll go if/when you go'.

(12b) hiyá?_cn ?at_hiyá?-xw.

go_1sUBJ WHILE_go-2sUBORDSUBJ

'I'll go when/while you go'.

The conjoined DP is preceded by the comitative conjunction $7 i$ :

(13) hiyá?_cn ii?_ca_ncát.

go_1sUBJ COM_DET_my father

'My father and I went' or 'I went with my father'.

These exhaust the types of constituents that can immediately follow a simple, sentence-initial predicate-enclitic.

4. Complex predicates and second-position clitics. The complex predicate constructions are assumed to be any that do not correspond to the patterns presented in 3 above. That is, we assume that we have a complex predicate construction whenever the sentence-initial full word-enclitic bundle is followed by something other than a determiner phrase, prepositional 
phrase, subordinate clause, or conjoined determiner phrase. What all such constructions have in common is that they have two or more predicative words with one subject and neither is subordinate to the other. Such is the case in examples (6) and (7). In order to show that there are in fact complex predicates in Klallam, it is first necessary to describe the placement of the speech-act enclitics.

It has been established, at least since Demers (1980), that the speech-act enclitics in Straits Salishan languages are strictly second-position clitics. The enclitic bundle forms a constituent itself that attaches to the first major word of the sentence. ${ }^{11}$ The sentences in (14) and in particular the complex predicate construction in (14c), a Klallam version of the Lummi example given by Demers (1980:13), show that the enclitic is the subject of the whole passive predicate complex and not just of the first predicate. $(14 c)$ is not merely a combination of $(14 a)$ and $(14 b)$, and the second predicate of $(14 c)$ is certainly not subordinate.

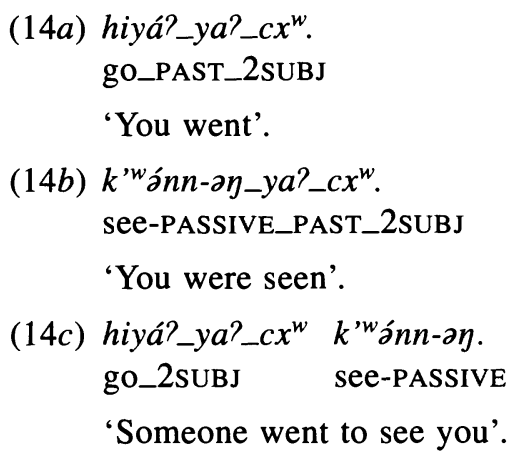

A characteristic typical of second position clitics is that they may be inserted to break up what one would expect to be an unbreakable constituent. Compare (15a) and $(15 b)$ :
(15a) 7úpn 7i?_či_tá?cs
ten COM_DET_eight
'eighteen'.
(15b) 7úpn_ya?_cn Ti?_či_tá?cs sči?ánay. ten_PAST_1subJ COM_DET_eight year

'I was eighteen years old'.

(15a) shows the normal method of forming numbers eleven through nineteen. 'Eighteen' is literally 'ten and an eight'. When 'eighteen' is the pred-

\footnotetext{
${ }^{11}$ Demers (1980) refers to the enclitic bundle constituent as AUX.
} 
icate, the subject and tense markers attach to the first word even though it breaks into the constituent 'eighteen'.

It can thus be seen that at least constructions such as (7) and (14c) with hiyá? are indeed complex predicates. Each is composed of two major constituents that may occur as independent predicates, but in these they each have one subject, which must, as in all other sentences, appear after the first word.

5. Categories of "auxiliaries." There is a limited class of lexical items that act as first elements in what we are assuming to be complex predicate constructions. These are presumably what the Thompsons were referring to as "auxiliaries." The major feature-other than syntactic position-that these auxiliaries have in common is their lack of morphology. ${ }^{12}$ While generally in Klallam there seem to be few limits on what morphology can appear on which words in a sentence, the auxiliaries are almost always bare roots. ${ }^{13}$ They are always underived intransitives. While each is formed of a root that may appear transitivized in other constructions (for example, hiyá? 'go' becomes hiyát $x^{w}$ 'take'), they are neither transitivized nor detransitivized when appearing as auxiliaries. While plural or diminutive morphology may appear on the main predicate or on any other full word in a sentence, neither may occur on the auxiliary. The same is true of aspect morphology, including the very common 'actual' imperfective aspect.

Although the auxiliaries have morphological and syntactic similarities, I show here that these items can be divided into at least four distinct categories based on their semantics and the morphological and syntactic details of the constructions in which they appear. The four categories are described in order: zero-class (5.1), ? $u$ ?-class (5.2), ? $i$ ?-class (5.3), and $c$-class (5.4). There is one apparent auxiliary (discussed in 5.5) that does not fall into any of these categories.

5.1 Zero-class auxiliaries and verbs. The zero-class auxiliaries are those that are immediately followed by the second predicate. Examples (7) and $(14 c)$ represent this class. In each of these, the predicate following the initial auxiliary-enclitic bundle has no proclitic; there is a zero connection

${ }^{12}$ This lack of morphology was also correctly noted by Poggi (1981).

${ }^{13}$ There are two apparent exceptions to the bare-root nature of the auxiliaries. The auxiliary

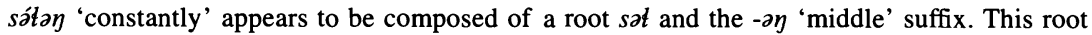
has, however, never been recorded without the ending, so sáta other exception is clearly a derived form. The auxiliary sstá $^{w} t z$ 'definitely' has a root $t x^{w}$ 'straight' with the common morpheme combination $7 s$ - 'stative' prefix, $-t$ 'durative' suffix, and $-a$ - 'resultative' infix. When not used as an auxiliary, this word has the meaning 'be straight' and the root appears in such words as $t x^{w} \partial \dot{t}$ 'steer' and $t x^{w} u$ st 'give a talking to, lit. straight-face someone'. 
between the two predicates. Four lexical items have been identified as clearly belonging to this class: hiyá? 'go', 'ən?á 'come', $\chi$ 'áy 'again', and húy 'finish'. ${ }^{14}$

5.1.1. hiyá? and ?an?á: a test for the category Verb. The two straightforward cases of zero-class auxiliaries are hiyá? 'go' and ?ən?á 'come'. These are common and occur with a wide variety of predicates, as shown in (16) and (17).

(16a) hiyá?_ca?n X'ácu.

go_1sUBJFUT fishing

'I'll go fishing'.

(16b) hiyá?_cn ?úx $x^{w} \quad$ ?a?_co_sút.

go_1suBJ go there OBL_DET_door

'I went over to the door'.

(16c) hiyá?_ya?_cn ?úył ?a?_ca_snáx $x^{w} t$.

go_PAST_1suBJ go aboard OBL_DET_canoe

'I went aboard the canoe'.

(16d) hiyá?_u_cx ${ }^{w} \quad$ Títn?

go_QUEST_2SUBJ eat

'Are you going to eat?'

(16e) hiyár_cn Titt.

go_1suBJ sleep

'I'll go to sleep'.

(16f) hiyá?_u_cx $x^{w}$ šátà?

go_QUEST_2SUBJ walking

'Are you going walking?'

(17a) ?an?áaya?_cn k'wánnay.

come_PAST_1suBj be seen

'Someone came to see me'.

(17b) ?an?á_cn ?úx $x^{w} \quad ? a ? \_c ̌ c ' x^{w} i c n$.

come_1suBj go there oBL_Port Angeles

'I came over to Port Angeles'.

(17c) ?an?á-ya?_cn ha?wí-st-ám

come_PAST_1sUBJ go forward-CAUS-PASSV

'They brought me up front'.

${ }^{14}$ Three other lexical items also seem to belong to this class: ?íya? 'be there', ?áta? 'be here', 7istá 'let's'. 
(17d) ?an?á_cn t'ák $i$.

come_1suBJ cross

'I came across'.

(17e)

$$
\begin{aligned}
& \text { ?an?á_u_ca?_cx } \quad \text { ?ítn? } \\
& \text { come_QUEST_FUT_2sUBJ } \\
& \text { 'Will you come eat?' }
\end{aligned}
$$

'We came up out of the water'.

For the examples in (16), the hiyá? could be removed, the enclitic bundle put after the next word, and the translation would not be much different. What the auxiliary adds is a focus on the motion and its direction with respect to the speech act.

Although the range of lexical items that may occur as second predicates in these zero-class constructions is large, it is not unlimited. In fact, words that may appear here also form a distinct class. Words that can function as stative predicates, i.e., qualities and nominals, may not occur as the second predicate. Sentences such as those in (18) are consistently rejected, though not beyond interpretation. ${ }^{15}$

$$
\begin{aligned}
& \text { (18a) *hiyá?_cn ša?šú?t. } \\
& \text { go_1suBJ happy } \\
& \text { (18b) *hiyá?_cn 7áy'. } \\
& \text { go_1suBJ good } \\
& \text { (18c) *hiyá?_cn nə?á?in. } \\
& \text { go_1suBJ my house }
\end{aligned}
$$

This gives us a straightforward syntactic test for membership in a lexical category Verb in Klallam: any lexical item that may appear as the second predicate in a zero-class complex predicate construction is a verb.

5.1.2. $x$ 'áy and húy: a further test for the category Verb. It might be argued that, since they are motion predicates, hiyá? and $2 \partial n$ 'á require only lexical items subject to motion as second predicates, and so the class is not entirely syntactically defined. Even if such nonmotion second predicates as 7itt 'sleep' (16e) and k'wnnay 'be seen' $(17 a)$ are put aside, the other two zero-class auxiliaries show that this is not the case.

While hiyá? and 7an?á function in two ways-either as independent predicates or as zero-class auxiliaries- $\chi$ 'áy and húy each have three possible

\footnotetext{
${ }^{15}$ Native speakers interpret these items in (18) as two sentences each. For example, 'I went. He's happy'. For meanings such as 'I went happy', 'I went well', or 'I went to my house', entirely different constructions are used.
} 
functions: independent predicates, zero-class auxiliaries, and $7 u$ ?-class auxiliaries. Their meaning and function as $7 u$ ?-class auxiliaries are described in 5.2. As independent predicate or zero-class auxiliary, $\lambda$ 'áy means 'again' and húy means 'finish'.

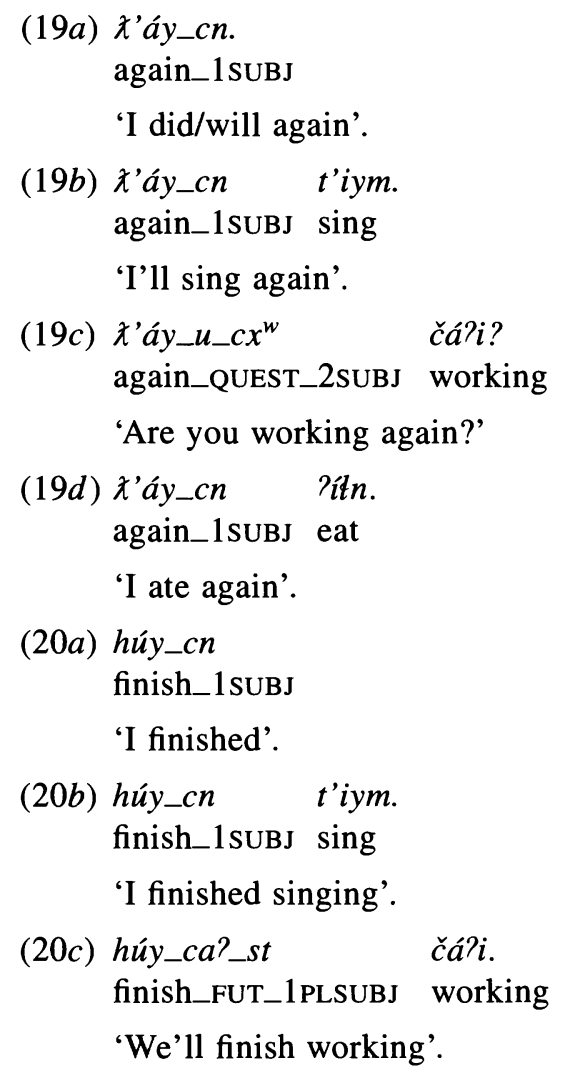

(19a) and (20a) show $\chi^{\prime} a ́ y$ and húy as independent predicates. Neither $\chi^{\prime}$ 'ay nor húy are motion predicates, but the class of lexical items that can appear as second predicates with them is the same as the class that can appear as second predicates with auxiliaries hiyá? and 'an?á. The second predicate may not be adjectival or nominal:

$$
\begin{aligned}
& \text { (21a) *オ'ay_cn ša'šú?t. } \\
& \text { again_1suBJ happy } \\
& \text { (21b) * x'ay_cn 'áy'. } \\
& \text { again_1subJ good } \\
& \text { (21c) *húy_cn n?á?in. } \\
& \text { finish_1suBJ my house }
\end{aligned}
$$


In order to convey ideas like 'I'm happy again' or 'I'm good again', the adjectival must be made a verb with derivational morphology, such as the verbal $t x^{w} a$ ?- 'mutative' prefix, which is frequently translated 'become' or 'get'. ${ }^{16}$ Compare (22) with $(21 a)$.
(22)
$\begin{array}{ll}\chi^{\prime} a y \_c n & t x^{w} a ?-\check{s} a \text { šút }^{\prime} . \\ \text { again_1sUBJ } & \text { MUT-happy }\end{array}$
'I got happy again'.

There are at least two ways of fixing (21c) so that it makes grammatical sense. These fixes involve putting a determiner in front of the second lexical item so that we have an entirely nonauxiliary construction. (23a) is a simple transitive and $(23 b)$ is a simple intransitive.
(23a) húy-tx $x^{w} \_c n$ ca_n?á?ìn.
finish-CAUSE_1SUBJ DET_my house
'I finished my house'.
(23b) húy ca_n?á?in.
finish DET_my house
'My house is finished'.

5.2. $\boldsymbol{?} u$ ?-class auxiliaries: $\boldsymbol{?} \boldsymbol{u}$ ? Adverbial Intensifiers. All of the auxiliaries listed by Thompson and Thompson (1971) and exemplified in (6) are in the $? u$ ?-class. The defining feature of this class is the required presence of the $? u$ ? proclitic on the second element. With eleven lexical items identified as belonging to this group, it is the largest class of auxiliaries. Each is illustrated in (24).

$$
\begin{aligned}
& \text { (24a) x'áy_cn ?u?_ša?̌ú } ? \text {. } \\
& \text { also_1sUBJ ?u?_happy } \\
& \text { 'I'm also happy'. } \\
& \text { (24b) húy_cn ?u?_hiyá?. } \\
& \text { only_1sUBJ ? } u \text { ? _go }
\end{aligned}
$$

\footnotetext{
${ }^{16}$ Gerdts and Hukari (2002) identify a class of "denominal" prefixes in Halkomelem. Cognate verbal prefixes exist in the Straits languages. These include $t x^{w}$ - 'buy' (which occurs in Northern Straits but not in Klallam), čsa'- 'come from', $t$ - 'partake', $\chi$ ' $a$ '- 'go to', $\check{c}$ - 'have', and $c$ t- 'be affected by'. The stem that these prefixes attach to is interpreted as the object of the verbal sense of the prefix. None of these is productive; the range of stems to which each may attach is small, idiosyncratic, and partly semantically determined. The $t$-, for example, occurs only on a few stems that refer to things that can be eaten, drunk, or smoked; it cannot even occur on all foods, and certainly does not provide a test of what can be called a "noun."
} 

(24c) to_cn ?u?_swáy'qa?.
just like_1sUBJ ?u?_man
'I'm just a man'.

(24d) sata_cn ?u?_q áq $q^{w} i$.

continuously_1SUBJ $? u$ ?_talking

'I'm talking continuously'.

(24e) cé ?at_cn ?u?_?ítn.

truly_1sUBJ ?u?_eat

'I truly ate'.

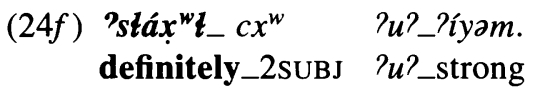

'You're definitely strong'.

$(24 g) \check{c} w^{\prime i n}$ 'cn $\quad ? u ? \_q^{w} a q^{w} i$.

even_1sUBJ ?u?_talking

'Even I am talking'.

$\begin{array}{rl}\text { (24h) } t u^{?} x^{w} \_c x^{w} & ? u ? \_? s \chi^{\prime} u ̛ \chi^{\prime} m . \\ \text { exactly_2sUBJ } & ? u ? \_ \text {correct }\end{array}$

'You're exactly right'.

(24i) xán'_st ?u?_t'íym.

all_1PLSUBJ ?u?_sing

'We all sing'.

(24j) ?u?ú?ya?_cn ?u?_?čáy.

beginning_PAST_1sUBJ ?u?_work

'I was at the beginning of work'.

(24k) mán'_cn ?u?_ša?šú?t.

very_1suBJ ?u?_happy

'I'm very happy'.

Note that in this construction the second element, the main predicate, is not restricted to verbs. Any word with appropriate meaning can be the second element here.

With one exception, all of the lexical items in this group may function as independent predicates. The exception is mán' 'very' (illustrated in $6 a$ and $24 k$ ), which requires a following ?u?-marked predicate. mán' cannot stand 
as an independent predicate itself, and it cannot occur with any of the morphology associated with predicative words. ${ }^{17}$ These facts indicate that mán' is, indeed, not a predicate but a member of a separate lexical category. If mán' is not a predicate, then this ' $u$ ? construction is not a complex predicate construction. The most appropriate name for the lexical category that mán' represents is Adverbial Intensifier. ${ }^{18}$ The $7 u$ ? clitic can be seen as a formative of an adverbial construction.

Since each of the other possible first elements in this construction has a similar function, they can be seen as derived adverbs. They are not morphologically derived but are derived by their position in the construction. Three characteristics of these constructions support this analysis. First, the semantics of each as represented in the translations in (24) are clearly adverbial. Each modifies the verbal or adjectival second element. Second, where possible, scope ambiguities arise just as one would expect from adverbs. For example, $(24 b)$ could also be translated 'only I am going', given the right context. Similarly, $(24 g)$ also means 'I'm even talking'. The third characteristic is the most striking: there is an unpredictable but consistent semantic shift, typical of derivation, between the adverbial and predicative functions of most of the words appearing as first elements in (24). This semantic shift can be seen by comparing (24a) and (24b) with the forms in (19) and (20). As an adverbial $\chi$ 'áy means 'also', while in other constructions it means 'again'. ${ }^{19}$ The adverbial húy means 'only', while in other constructions it means 'finish'. Minimal pairs are shown in (25) and (26).

$$
\begin{aligned}
& \text { (25a) đ'áy_cn t'íym. } \\
& \text { again_1suBJ sing } \\
& \text { 'I'll sing again'. } \\
& \text { (25b) đ'áy_cn ?u?_t'íym. } \\
& \text { also_1sUBJ } ? u \text { ? _sing } \\
& \text { 'I'll sing, too'. }
\end{aligned}
$$

\footnotetext{
${ }^{17}$ Like the other auxiliaries, the root mán' may be transitivized with the causative suffix $-t x^{w}$. The resulting form mán' $t x^{w}$ means something like 'intensify' and is not an auxiliary. This is the only morphology recorded occurring with this very common root.

${ }^{18}$ Arregui and Matthewson (2001) demonstrate for Lillooet that there is no open class of Adverb. The situation is the same in the Straits languages. In order to say something like 'he walked slowly', constructions corresponding to 'he was slow when he walked' or 'his walking was slow' must be used.

${ }^{19}$ The Saanich cognate $\lambda^{\prime} e$ ? patterns the same way: when followed by $7 a w^{\prime}$ it means only 'also'; in other constructions it means only 'again'. Just as in Klallam there are no exceptions to this in the corpus, and native speakers are consistent in elicitation. Perhaps Lummi or Samish is different in this respect. Jelinek (1990:182) shows the Lummi/Samish cognate in a sentence with 'əow' and glosses it as ambiguous between 'again' and 'also'.
} 
(26a) húy_cn t'íym.

finish_1suBJ sing

'I finished singing'.

(26b) húy_cn ?u?_t'íym.

only_1SUBJ ?u?_sing

'Only I sang'.

A summary of the semantic shifts is given in (27).

\begin{tabular}{|c|c|c|}
\hline t'áy & $\begin{array}{l}\text { In } ? u \text { ? CONSTRUCTION } \\
\text { 'also' }\end{array}$ & $\begin{array}{l}\text { In OTHER CONSTRUCTIONS } \\
\text { 'again' }\end{array}$ \\
\hline húy & 'only' & 'finish' \\
\hline tán & 'just like' & 'detach' \\
\hline sátà & 'continuously' & 'continue' \\
\hline ?at & 'truly' & 'tell the truth' \\
\hline$t^{\prime} x^{w} t$ & 'definitely' & 'be straight' \\
\hline 'in' & 'even (so)' & 'not even (so)' \\
\hline & 'exactly' & 'be in the middle' \\
\hline
\end{tabular}

These meaning differences are consistent among different speakers and are essentially the same in Northern Straits and Klallam. For some of the items, the semantic connection is obvious (célat, for example), while for others it is vague $\left(t u^{\prime} x^{w}\right)$ but recoverable. For tán, the connection is obscure. The adverbial meaning of tán is difficult to translate with a simple gloss. The examples in $(28 a)-(28 g)$ show its range as an adverbial; $(28 h)$ shows its use as a predicate.
(28a) tán_cn
?u?_xčit.
just like_1suBj $2 u ? \_$know it
'I really know it'.
(28b) táy_cn
just like_1suBJ ?u?_saw it
'I just saw it'.
(28c) láy_cn ?u?_swáy'qa?.
just like_1suBJ ?u?_man
'I'm a real man/I'm just a man'.
(28d) tán_u_c $x^{w}$ ?u?_hiyá?? just like_QuEST_2sUBJ $? u$ ?
'Are you really going?'
$\begin{array}{ll}\text { (28e) lán } & \text { ?u?_péq'. } \\ \text { just like ?u?_white }\end{array}$
'It's really white/It's almost white'. 
$\begin{array}{cl}\text { (28f) láy_cn } & ? u \text { ? _si?ám'. } \\ \text { just like_1suBJ } & ? u \text { ? _rich }\end{array}$

'I'm just like I'm rich [context: getting a ride in a limousine]'.

(28g) láy_cx $x^{w} \quad$ u?_sq $q^{w}$ máy.

just like_2suBJ $2 u$ ? _dog

'You're just like a dog [an insult]'.

(28h) tán_cn

detach_1suBJ

'I'm off (what I was stuck on)'.

For 'čw'in', the difference is surprising. Unlike the other meaning differences, where the meaning in the first column occurs only in the $? u$ ? construction while the meaning in the second column occurs in all other constructions, the 'not even' reading of 'čw'in' occurs only when it has a third-person subject and is followed by a determiner phrase marked for possession. It is not clear how this construction contributes to the meaning 'not even' since there is no negative element, and when čw'in' occurs alone it means 'even'. Examples of $\check{c} w$ 'in' are shown in (29).

(29a) čw'in'_cn ?u?_čpaypsénts.

even_1sUBJ ?u?_have five cents

'Even I have five cents'.

(29b) čw'ín' či_nsu'čpaypsénts.

not even DET_my having five cents

'I don't even have five cents'.

(29c) čw'in'_cn ?u?_k'wənnúpa.

even_1subJ $? u$ ? _see you

'I even saw you'.

(29d) čw'ín' či_nsk'wannúya.

not even DET_my seeing you

'I didn't even see you'.

(29e) $\check{c} w^{\prime} i n^{\prime} \_c n$.

even_1suBJ

'Even I (do)'.

The list in (27) has only eight of the eleven. As mentioned above, mán' occurs only in the adverbial construction, so is not listed. Of the other two, xán' 'all' is very common and, though it usually does appear with the following $? u$ ? it can appear without it and without a change in meaning. 
Unlike all of the other ' $u$ ?-class adverbs, it seems that xán' can occur as an adverbial, a predicate, or as an adjective.

The final adverbial, $? u u^{\prime} \dot{u}$ (exemplified in $24 j$ ), is rare in the corpus. There are not enough data to determine if it has some other function. It, apparently, has no cognate in Northern Straits.

Note that when the stem shifts semantics in the adverbial construction it usually becomes an intensifier. It seems likely that the one purely lexical adverbial, mán', is the syntactic and semantic prototype for these derived adverbs.

Perhaps these are not adverbs derived from predicates but separate lexical items distinct from the homophonous predicates. If so, these lexical items never appear in any other syntactic context and are thus of the distinct category Adverbial Intensifier.

5.3. $i$ ?-class auxiliaries: $i$ ' Adverbs. A group of lexical items similar to the $? u$ ? adverbs have the clitic $7 i$ rather than $? u ?$ preceding the main predicate. This is a much smaller set having only three basic members:

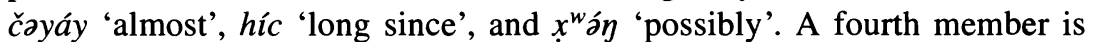
derived from the first just mentioned, $k^{w} \downarrow c ̌ a y a ́ y ~ ' s o o n '$, with the 'realized' prefix $k^{w} t$-. These are illustrated in (30).

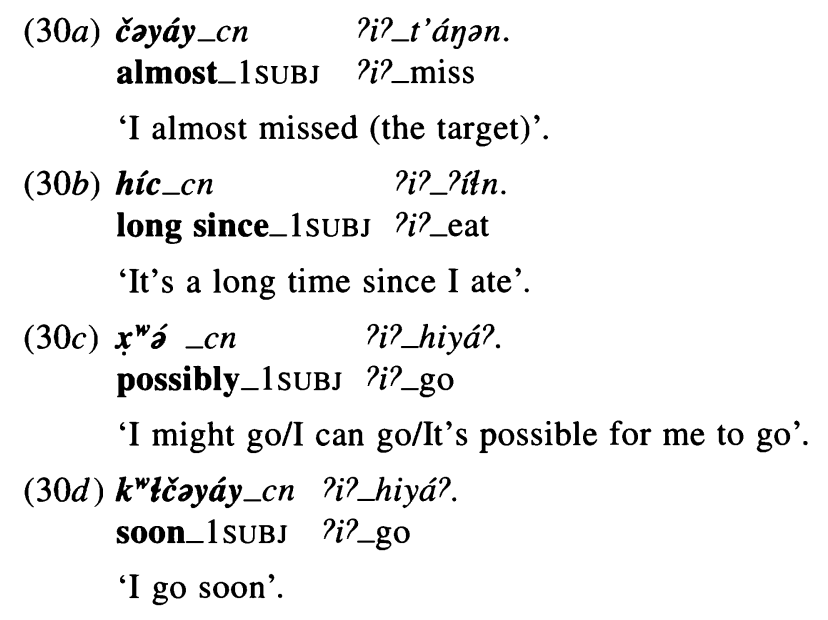

Just as with most of the $? u$ ? adverbs, all four of these may be independent predicates and, just as with most of the $7 u$ adverbs, each of the three basic forms has an unpredictable semantic shift. (31) shows the semantic shifts. ${ }^{20}$ 
(31)

$\begin{array}{lll} & \text { IN } 7 i \text { ' CONSTRUCTION } & \text { IN OTHeR Constructions } \\ \text { čayáy } & \text { 'almost' } & \text { 'barely' } \\ \text { híc } & \text { 'long since' } & \text { 'long duration' } \\ x^{w} \text { ź } \eta & \text { 'possibly, might, can' } & \text { 'quick, fast' }\end{array}$

Examples of each of these in other constructions are shown in (32).

(32a) čayáy ca_nsu?t'ánan.

barely DET_my missing

'I barely missed (the target)'.

(32b) hic

$k^{w} i \_n a s ? i t n$.

long duration DET_my eating

'I ate a long time'.

(32c)
$x^{w} \partial \dot{y} \_c n$ ?at_hiyá?-n.
quick_1sUBJ WHILE_go-1ss
'I'm quick when I go'.

The relationship between the two functions of čayáy is very similar to the relationship between the two functions of the ' $u$ ? adverbial c c $w$ ' $i n$ ' 'even; not even' illustrated in (29). In each, the meaning in its nonadverbial function is negative with respect to its meaning as an adverbial. The sentence in (30a) implies that the target was hit by a narrow margin, while (32a) implies that the target was not hit by a narrow margin. Also, the morphological and syntactic requirements are the same: the nonadverbial use for each requires a third-person subject and a determiner phrase marked for possession.

What these $? i$ ? adverbs have in common in contrast to the ? $u$ ? adverbs is reference to time. Though čayáy can be used for both time and space, when

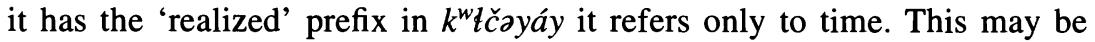
historically related to the semantics of the $7 i$ ? proclitic.

\subsection{On the distinction between $\boldsymbol{i}^{\boldsymbol{P}}$ and $\boldsymbol{P}^{\boldsymbol{M}} \boldsymbol{\text { ? }}$ and their functions with} different categories. There are at least two separate morphemes, proclitic or prefix, with the form $7 i$. One is an aspectual prefix that indicates continuing motion. The other is the comitative conjunction mentioned in $\mathbf{3}$ above. Both are illustrated in one compound sentence in (33), showing that they are two different morphemes.

$$
\begin{aligned}
& \text { xát_cn ?i?_?i?-šátaj_cn. } \\
& \text { sick_1suBJ COM_CONTIN-walking-1 suBJ } \\
& \text { 'I'm sick and I'm walking'. }
\end{aligned}
$$

it as one of the $7 u$ ? adverbs ("second order predicate") but gives no examples. This is a fairly frequently occurring word in both Klallam and Saanich and it has never been recorded with a following $7 u$ ? 
(33) has an equivalent sentence with conjunction reduction, shown in (34).

$$
\begin{aligned}
& \text { xát_cn } \quad \text { i?_?i?-šátà. } \\
& \text { sick_1sUBJ } \text { COM_CONTIN-walking } \\
& \text { 'I'm sick and I'm walking'. }
\end{aligned}
$$

Note that the form of (34) is superficially the same as the $i$ ? adverbial constructions in (30). They are not the same constructions, however, since, when a main clause subject for the second predicate is added, the meaning is changed, becoming two separate clauses as in (35), which native speakers find of marginal acceptability. Compare (35) with (30a).

$$
\begin{aligned}
& \text { čayáy_cn } \quad 2 i ? \_t \text { 'ánan_cn. } \\
& \text { barely_1sUBJ COM_miss_1sUBJ } \\
& \text { 'I barely did it and I missed'. }
\end{aligned}
$$

The conjunction $7 i$ ? has inherent temporal semantics; it conjoins only simultaneous events. It differs both from a logician's 'and' that conjoins predicates regardless of temporal relationship and from a sequential 'and' that implies the event of the first conjunct precedes the second in time. This was recognized by Thompson and Thompson (1971) with their "accompanying" label, by Efrat's (1969) gloss "simultaneity" for the Sooke cognate, and by Raffo's 1972 gloss "simultaneous" for Songish. The fact that the ?i? adverbs each have time-related semantics, while none of the $? u$ ? adverbs do, indicates that the $? i$ ? of the adverbial construction must be historically related to the conjunction $7 i$ ?

Thompson and Thompson (1971) and Montler (1986) call the $2 u$ ? "contemporaneous," Poggi (1981) labels it "aspect," and Jelinek (1990) labels it "link." While only Jelinek identifies it as crucial to the adverbial construction, all identify this $? u ?$ with an $? u ?$ proclitic that appears in clause-initial position and indicates discourse or extralinguistic contrast. Though they are perhaps historically related, these are synchronically distinct. The contrast marker appears in sentences such as ?u?_šátoy_cn 'I'm walking'. The sentence without the ? $u$ ? is also translated 'I'm walking', but native speakers consistently use contrastive intonation in the English translation of the form with the $? u$ ? . Generally, this initial $? u$ ? means something like 'contrary to what one might think' or 'in contrast to the previous context'. Out of context this $? u$ ? is optional. The $? u$ ? in the "auxiliary" construction is NOT optional and never carries semantic or pragmatic function. It is strictly a construction formative.

When the $7 i$ ? conjunction and $? u$ ? contrast marker both appear before a second predicate, the translation usually includes 'but', as in (36). ${ }^{21}$

\footnotetext{
${ }^{21}$ When ${ }^{2} i$ and ${ }^{2} u ?$ appear together, the phonetic result is usually $y u$ ?
} 
(36)
xát_cn ?i?_?u?_?i?-šátà.
sick_1SUBJ COM_CONTRAST_CONTIN-walking
'I'm sick but I'm walking'.

5.5. $c$-class auxiliaries: Negative Adverbs. The $c$-class auxiliaries are a class of only two lexical items: 'áwa 'not' and $7 \hat{u} ? a$ ? 'not yet'. These both require that the following main predicate be preceded by the $c$ proclitic or prefix. This $c$ is probably cognate with the Thompson $k a$ 'unrealized' particle (Thompson and Thompson 1992:150) and the Moses-Columbia 'unrealized' prefix kas- described by Mattina (1997:331). The Thompson and Moses-Columbia negative constructions look very similar to the Klallam pattern. Unlike the cognates, however, the distribution of the Klallam $c$ is extremely limited-it occurs only before predicates following ?áwa and $2 \hat{u}\urcorner a ?{ }^{22}$ Examples of $? a ́ w a$, a very common word, are shown in (37) and of ? $u^{\prime} ? a$ ?, much less common in the corpus, in (38).
(37a) Táwa c_hawíy.
not C_return
'She didn't return'.

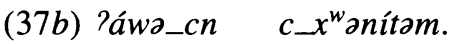
not_1suBJ C_white person
'I'm not a white man'.
(37c) ?áwa_cx $c^{w} \quad c$ čá?sa.
not_2suBJ C_two people
'There aren't two of you'.
(37d) ?áwa c_nák $k^{w}$.
not C_you
'It's not you'.
(37e) ?áwa_cn c_k’ánn-ay.
not_1sUBJ C_see-PASSIV
'I wasn't seen'.
(37f) 'áwa_cn c_?áy'.
not_1suBj C_good
'I'm not well'.

\footnotetext{
${ }^{22}$ The situation in Klallam is clearer than in Northern Straits. The Northern Straits cognate is $s$ (Montler 1986:191), merging phonologically with other $s$ prefixes. Once all the $s$ 's are properly sorted out, the pattern in Northern Straits seems to be the same as Klallam.
} 


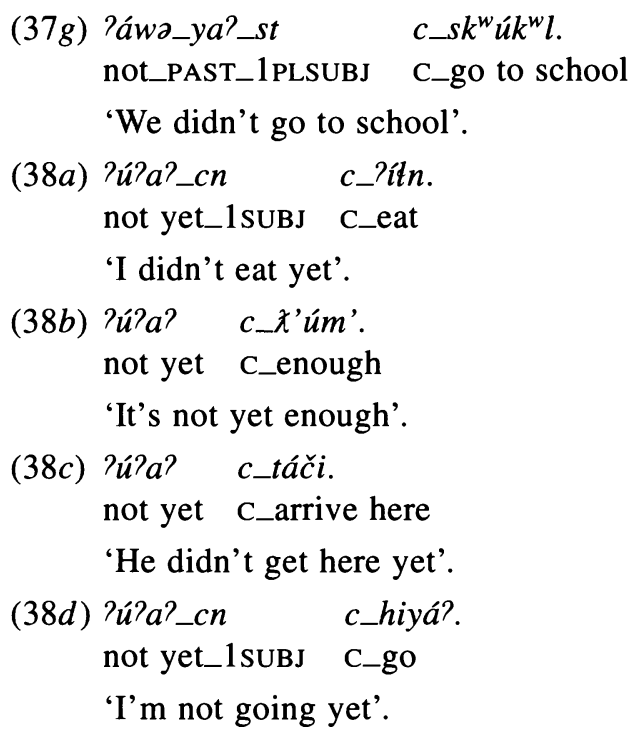

?áwa can stand alone as a negative answer to a yes/no question. Aside from that and from the adverbial function shown in (37) and (38), both of these negative words can be predicative. Either word may occur with a subject and no following predicate, as illustrated in (39).

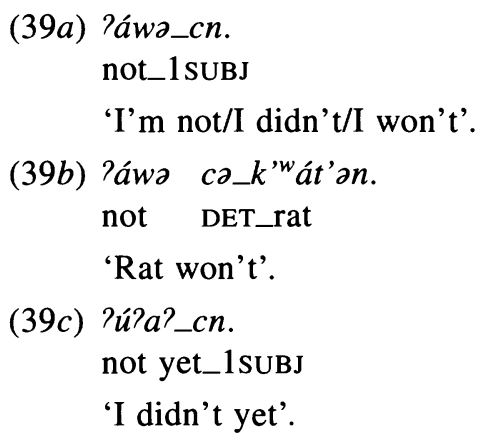

5.6. hú " conjoined conditional. hú? may fit the definition of "auxiliary" or "adverbial," but it has a unique distribution that distinguishes it from the other "auxiliaries" and, indeed, from all other roots. This root never takes any morphology and occurs in only one construction. It is used in a construction that is the most common way of expressing a conditional statement. A conjoined conditional construction uses a sentence-initial root $h u^{\prime}$, as illustrated in (40).

(40) hú?_ca?_cx hiyá? 2i?_hiyá?_ca?n. if/when_FUT_2sUBJ go COM_go_1FUTSUBJ 'I'll go if/when you go'. 
The hü? root in (40) seems to pattern with the zero-class auxiliaries discussed in 5.1-hü? and its enclitics are immediately followed by a main predicate. It differs from them in two respects, however. First, hú? is never predicative itself; it must always be followed by a predicate. So forms like *hú?_ca? $c x^{w}$ are unacceptable alone. The second difference is that it must be the first word of the first of a pair of conjuncts; it never occurs in a simple, noncompound sentence. So forms like *hú?_ca? $c x^{w}$ hiyá? are unacceptable alone. The two conjuncts must appear with the hú? clause first, so *hiyá? $c a ? n$ ? $i$ hú?_ca? $c x^{w}$ is unacceptable. This is unique in that, with its main-clause subject, it has the form of an independent clause but cannot occur independently.

6. Transitive main verbs with auxiliaries and adverbs. Another interesting difference between the true auxiliaries (zero-class) and the adverbs is in the interpretation of an immediately following determiner phrase. As established in 5.1, the identifying feature of the true auxiliaries is the immediately following verb. In all of the examples in that section the main verb is intransitive. While intransitive verbs usually occur with the auxiliaries, a transitive verb is also possible. Examples are shown in (41). Compare especially (17a) with (41a).

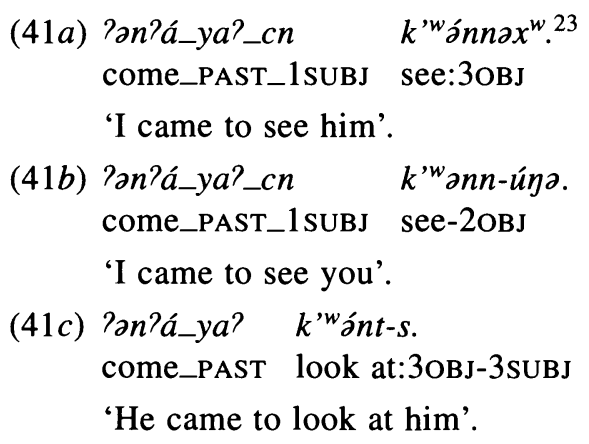

The third-person transitive subject is not an enclitic, as are the first and second persons, but a suffix that remains on the main verb and does not move to second position. An explicit third-person object determiner phrase must follow the main verb, as illustrated in (42). ${ }^{24}$

$$
\begin{aligned}
& \text { ?an?á_ya? k'wánt-s ca_snáx } x^{w} z \text {. } \\
& \text { come_PAST look at:3OBJ-3SUBJ DET_canoe }
\end{aligned}
$$

${ }^{23}$ The third-person object is zero. This word has the $-n \partial x^{w}$ 'noncontrol' transitivizer.

${ }^{24}$ It is not actually possible to distinguish structurally between the interpretation given in (42) and an interpretation where (42) is two sentences: 'He came. He looked at the canoe'. The same is true of (43), which could be 'He came. The canoe was looked at by the man'. 
An important feature of auxiliaries is that mention of an explicit agent in a determiner phrase requires the use of the passive, as in (43).
?an?á_ya? k’wánt-à
ca_snáxwit ?a?_ca_swáy'qa?.
come_PAST look at-PASSIV DET_canoe OBL_DET_man
'The man came to look at the canoe'.

Up to a point, the adverbs pattern similarly. Compare the examples in (44) with those in (41), (42), and (43).
(44a) čw'ín'_cn ?u?_c'sát.
even_1sUBJ ? $u^{2} \_$hit:3OBJ
'I even hit him'.
(44b) čw'ín'_cn ?u?_c'sác. even_1suBJ ?u?_see:2OBJ
'I even hit you'.
(44c) čw'ín' ?u?_c'sót-s.
even ?u?_hit:3OBJ-3suBJ
'He even hit him'.
(44d) čw'ín'
?u?_c'sát-s ca_ncát.
even $? u$ ? hit:3OBJ-3sUBJ
DET_my father
'He even hit my father'.
(44e) čw'ín' ?u?_c'sát-à ca_ncát ?a?_ca_swáy'qa?. even ?u?_hit-PASSIV DET_my father OBL_DET_man
'The man even hit my father' or 'My father was even hit by the man'.

As described in 5.2, the adverbial differs from the auxiliary in that the construction-defining characteristic is not an immediately following verb but a following $? u$ ?-marked predicate. The adverbial also differs from the auxiliary in that the passive is NOT required when a transitive agent is explicitly mentioned in a determiner phrase. The subject determiner phrase comes before the $7 u$-marked predicate. Compare (44d) with (45).
čw'ín' co_ncát
?u?_c'sát.
even DET_my father ?u?_hit:3ОBJ
'My father even hit him'.

The adverbial construction allows the agent determiner phrase to be explicitly mentioned without resorting to the passive. The agent precedes the main verb, and the $-s$ third-person transitive subject marker is missing from the verb in this construction. Example (46) shows the auxiliary ?an?á in a construction parallel to that in (45). 


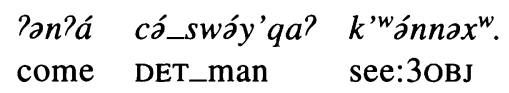

'The man that saw him came'.

The determiner phrase here cannot be interpreted as the subject of the second verb, and this sentence cannot be interpreted as an auxiliary/complex predicate construction. The only possible interpretation is as a simple predicate with a relative clause construction as subject. Relative clauses in Klallam are essentially the same as in Saanich (Montler 1993). In (46), swáy'qa? is the head and $k^{\prime w}$ ánnox ${ }^{w}$ is the restricting clause, while ?an'á is the main verb.

7. Adjectives and Nouns. Though no one has referred to any of the components of constructions like the one in (47) as "auxiliaries," this construction has been called a complex predicate.

$$
\begin{array}{ll}
\text { čáq_cxw } & \text { swáy'qa?. } \\
\text { big_2sUBJ } & \text { man }
\end{array}
$$

'You are a big man'.

Jelinek (1990:188) identifies constructions such as (47) with what we have been calling the zero-class or true auxiliaries, discussed in 5.1. They do indeed look similar to those complex predicates. As shown in (48), both of the words in (47) can be predicative and there is nothing else between them.

(48a) čáq_cx $x^{w}$.

big_2suBJ

'You are big'.

(48b) swáy'qa?_cxw.

man_2sUBJ

'You are a man'.

The construction in (47) does differ, however, from the auxiliary constructions both semantically and distributionally. Semantically, in this construction the first word is always a quality and the second is always nominal, never verbal. In contrast, the four auxiliaries of $\mathbf{5 . 1}$ are always followed by a verb, never by an adjectival or nominal word. This alone suggests that we have at least a separate category of auxiliary whose defining characteristic is that it must be followed by a nominal predicate. As a corollary to that, we must have a category of nominal predicates that may follow these adjectival auxiliaries.

A more definitive difference between these adjectivals and the auxiliaries is that these can take regular morphology. As noted in $\mathbf{5}$ above, one of the defining characteristics of the auxiliaries (and the adverbs) is that they 
participate in no regular morphological processes-they are typically bare stems. The adjectivals, in contrast, may be, and in some cases must be, marked with the collective plural morphology.

It is necessary, first of all, to point out that plural marking is not obligatory in Klallam. Both examples in (49) are acceptable and are synonymous. (49a) shows the singular form for 'man' and (49b) shows the reduplicated plural.

(49a) čá'sa? swáy'qa?

two man

'two men'

(49b) čá'sa? sw'wáy'qa?

two men

'two men'

The adjectival in (47) may be pluralized with a singular nominal following, as in (50).

(50) čáyq_cx $w^{w}$ hay swáy'qa?.

bigPL_2sUBJ_2PL man

'You are big men'.

And, just as in (49b), the nominal may also be plural, as in (51).

(51) čáyq_cx $x^{w} \_$hay sw'wáy'qa?. bigPL_2SUBJ_2PL men

'You are big men'.

But when the nominal is plural, the adjectival is also required to be plural. So (52) is unacceptable.

(52) *čáq_cxw_hay sw'wáy'qa?. big_2SUBJ_2PL men

This agreement is required not only in predicates but also in determiner phrases. (53) shows the same pattern as (47) and (50)-(52).

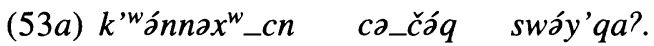

see:3OBJ_1sUBJ DET_big man

'I see the big man'.

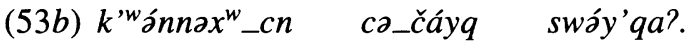

see:3OBJ_1SUBJ DET_bigPL man

'I see the big men'.

(53c) k’wánnax _w co ca_čáyq sw'wáy'qa?.

see:3OBJ_1sUBJ DET_bigPL men

'I see the big men'. 


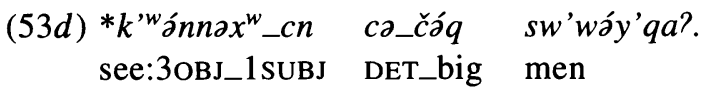

There is one further restriction on these forms: the order of the words in (47) cannot be reversed, as shown in (54).

(54) *swáy'qa?_cx č čáq.

The adjectival čáq must be in a separate category from the nominal swáy'qa?.

The special semantic, morphological, and syntactic restrictions on the categories of words such as those shown in (47) lead us to conclude that they are distinct categories from each other and that neither is in the same category as the auxiliaries. They are not adverbs nor do they pass the test for the category verb discussed in 5.1.1 and 5.1.2. The most appropriate category names for words like čá $q$ and swáy'qa? are Adjective and Noun, respectively.

8. An unrelated piece of evidence. Examples (55) and (56) show typical simple transitive clauses.

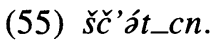

'I hit it'.

(56) hámant_cn.

'I hammered it'.

When such roots of high semantic transitivity occur bare without the $t$-transitivizing suffix the normal interpretation of the subject is as patient, or undergoer, as in (57). ${ }^{25}$ These are unaccusatives or what Thompson (1979b) called the noncontrol roots.

(57) šáč'_cn.

'I got hit'.

But such an interpretation is not possible with the root /hámən/. The only possible interpretation for (58), which is parallel to (57), does NOT have the expected patient subject. The only possible interpretation is semantically anomalous.

(58) háman_cn.

'I am a hammer' (NOT 'I got hammered').

This small piece of evidence alone indicates that /həmən/ must belong to a separate category that looks very much like what we would call a noun.

${ }^{25}$ Roots in Klallam and Northern Straits can be classified, independently of the categories noun and verb, based on their inherent semantic transitivity (Montler 1989). Two-participant roots of high effect (with meanings like 'hit', 'cut', etc.) may occur bare with a patient subject, while two-participant roots with low effect ('know', 'see', etc.) may not occur bare. There are at least five such classes of roots. 
9. Conclusion. By considering their surface syntactic and morphological distribution, the "auxiliaries" of Thompson and Thompson (1971) are shown to be a different grammatical category from those of Thompson $(1979 a)$. There is a small class of complex predicate-forming lexical items in Klallam that can be called "auxiliaries." Only four have been identified thus far. The auxiliaries are shown to be distinct from adverbs. Once the category "auxiliary" is established, we are able to find a simple, superficial distributional test for membership in a grammatical category "verb."

We can identify three categories of "adverbial intensifier" depending on what proclitic the adverbial requires on the main predicate: $? u$ ?-class, $7 i$ ?class, or $c$-class. The distinct semantic shift of adverbs that function in other constructions as predicates shows that they form a category distinct from verbs and other predicative categories. The adverbs are also shown to be distinct from the auxiliaries in the syntax of determiner phrase agent placement when the main verb is third-person transitive.

Finally, the grammatical categories "adjective" and "noun" are established by their distribution in contrast to auxiliaries in complex predicates. While auxiliaries are never morphologically marked, an adjective must be marked for the collective plural if its accompanying noun is collective plural.

The grammatical patterns described here for Klallam are essentially the same in Northern Straits. These categories were arrived at by looking at the surface distribution of lexical items IN CONSTRUCTIONS. No reference was made to particular morphology allowed on particular lexical items independent of the constructions in which they appear.

Klallam and other Salishan languages are unlike most languages-for example, a Muskogean language like Alabama-where, although there is no 'be' verb, a number of simple morphological tests for membership in the categories "noun" and "verb" can be found during the first few fieldwork sessions. Alabama nouns and verbs differ in diminutive, number, aspect, and negative morphology. In contrast, almost any lexical item in Klallam can be predicative, plural, diminutive, imperfective, transitivized, and so on, with uniform morphology. What is surprising is that in languages having as much morphology as Klallam, Northern Straits, and other Salishan languages, there seems to be a scarcity of general, simple, morphological tests for membership in syntactic categories. Although with the evidence continuing to accumulate from across the Salishan family it now seems certain that we can identify distinct grammatical categories, the languages are no less amazing.

\section{REFERENCES}

Arregui, Ana, and Lisa Matthewson. 2001. A cross-linguistic perspective on the expression of manner. Papers for the Thirty-sixth International Conference on Salish and 
Neighbouring Languages, University of British Columbia Working Papers in Linguistics, ed. L. Bar-el, L. T. Watt, and I. Wilson, pp. 1-24. Vancouver.

Davis, Henry; I-Ju Sandra Lai; and Lisa Matthewson. 1997. Cedar roots and singing detectives: attributive modification in Salish and English. Papers for the Thirty-second International Conference on Salish and Neighboring Languages, pp. 291-316. Port Angeles, Wash.: Elwha Klallam Tribe.

Demers, Richard. 1980. The category aux in Lummi. Paper presented at the Fifteenth International Conference on Salish Languages, Vancouver.

EFrat, BARBARA S. 1969. A grammar of nonparticles in Sooke, a dialect of Straits Coast Salish. Ph.D. dissertation, University of Pennsylvania.

Gerdts, Donna B., AND Thomas E. Hukari. 2002. Halkomelem denominal verbs. Paper presented at the 2002 meeting of SSILA, San Francisco.

HAAG, MarCIA. 1998. Word-level evidence for lexical categories in Salishan languages. IJAL 66:379-93.

JaCOBSEN, William H., JR. 1979. Noun and verb in Nootkan. The Victoria Conference on Northwestern Languages, ed. Barbara S. Efrat, pp. 83-155, British Columbia Provincial Museum Heritage Record no. 4. Victoria: British Columbia Provincial Museum.

JelineK, Eloise. 1990. Quantification in Straits Salish. Papers for the Twenty-fifth International Conference on Salish and Neighbouring Languages, pp. 177-94. Vancouver: University of British Columbia.

Jelinek, Eloise, and Richard Demers. 1994. Predicates and pronominal arguments in Straits Salish. Language 70:697-736.

KINKADE, M. Dale. 1983. Salish evidence against the universality of "noun" and "verb." Lingua 60:25-39.

Kuipers, Aert H. 1968. The categories verb-noun and transitive-intransitive in English and Squamish. Lingua 21:610-26.

Matthewson, Lisa, AND Henry Davis. 1995. The structure of DP in St'át'imcets (Lillooet Salish). Papers for the Thirtieth International Conference on Salish and Neighbouring Languages, pp. 54-68. Victoria: University of Victoria.

Matthewson, Lisa, and Hamida Demirdache. 1995. Syntactic categories in St'át'imcets (Lillooet Salish). Papers for the Thirtieth International Conference on Salish and Neighbouring Languages, pp. 69-75. Victoria: University of Victoria.

Mattina, Anthony, and Nancy Mattina. 1995. Okanagan $k s$ - and $k t$-. Paper presented at the Thirtieth International Conference on Salish and Neighbouring Languages. Victoria: University of Victoria.

Mattina, Nancy. 1996. Aspect and category in Okanagan word formation. Ph.D. dissertation, Simon Fraser University.

1997. Moses-Columbia imperative constructions: a working paper. Papers for the Thirty-second International Conference on Salish and Neighboring Languages, pp. 325-37. Port Angeles, Wash.: Elwha Klallam Tribe.

Montler, Timothy. 1986. An Outline of the Morphology and Phonology of Saanich, North Straits Salish. Occasional Papers in Linguistics, no. 4. Missoula: Linguistics Laboratory, University of Montana.

1989. The independence of transitivity and control in Saanich. Paper presented at the Linguistic Association of the Southwest, San Antonio, Texas.

1993. Relative clauses and other attributive constructions in Saanich. American Indian Linguistics and Ethnography in Honor of Laurence C. Thompson, ed. A. Mattina and T. Montler, pp. 241-64, University of Montana Occasional Papers in Linguistics, no. 10. Missoula: Linguistics Laboratory, University of Montana.

1996. Some Klallam paradigms. Papers for the Thirty-first International Conference on Salishan and Neighbouring Languages, pp. 257-63. Vancouver: Linguistics Department, University of British Columbia. 
1999. Language and dialect variation in Straits Salishan. Anthropological Linguistics 41, no. 4:462-502.

Poggi, Claudine. 1981. Klallam auxiliaries: a subclass of predicatives. Working Papers of the Sixteenth International Conference on Salishan Languages, pp. 63-69, University of Montana Occasional Papers in Linguistics, no. 2. Missoula: Linguistics Laboratory, University of Montana.

RafFo, Yolanda. 1972. A phonology and morphology of Songish, a dialect of Straits Salish. Ph.D. dissertation, University of Kansas.

ThOMPSON, LAURENCE C. 1979a. On the development of auxiliaries in Salish. University of Hawaii Working Papers in Linguistics 11, no. 2:67-73.

. 1979b. The control system: a major category in the grammar of the Salishan languages. The Victoria Conference on Northwestern Languages, ed. Barbara S. Efrat, pp. 156-76. British Columbia Provincial Museum Heritage Record no. 4. Victoria: British Columbia Provincial Museum.

Thompson, Laurence C., AND M. Terry Thompson. 1971. Clallam: a preview. Studies in American Indian Languages, ed. Jesse Sawyer, pp. 251-94, UCPL 65. Berkeley and Los Angeles: University of California Press.

1992. The Thompson Language. Occasional Papers in Linguistics, no. 8. Missoula: Linguistics Laboratory, University of Montana.

VAN EIJK, JAN P., AND Thom Hess. 1986. Noun and verb in Salish. Lingua 69:319-31. 